\title{
Clinical value of echocardiographic colour image processing in two cases of primary cardiac tumour
}

\author{
LINDSEY D ALLAN, MICHAEL C JOSEPH, MICHAEL TYNAN \\ From the Department of Paediatric Cardiology, Guy's Hospital, London
}

SUMMARY We present two cases of cardiac tumours presenting in infancy in which the use of a colour image processor was found to be of assistance in the interpretation of the two dimensional: echocardiogram. In the first case the colour image highlighted the presence of multiple tumorous deposits suggesting a diagnosis of tuberous sclerosis. In the second case the site and extent of the tumour attachment to the ventricular septum could be more clearly distinguished echocardiographi- cally when studied in colour.

Difficulties in differentiation by the human eye of shades of grey on a two dimensional echocardiographic image have led to the development recently of a colour image processor. This allows differences in tissue reflectivity to be qualitatively and quantitatively assessed. ${ }^{1}$ Preliminary results in the clinical application of amplitude processing are promising. This is particularly so in the study of myocardial disease in adults where fibrous change might be expected to alter the intensity of the returning echoes. This change can be more readily detected by colour processing and using standard gain control setting measured quantitatively.

We have applied the image processing technique to two cases of cardiac tumour presenting in infancy. In each case the quality of the tumour tissue could be differentiated from normal myocardium more readily using the colour module and this was of particular use in defining the extent of invasion of the tumour tissue within the normal myocardial tissue.

\section{Patients and methods}

Both patients were examined echocardiographically using a Mark III Advanced Technical Laboratories two dimensional scanner and a $5 \mathrm{MHz}$ transducer. Videorecording was made on a Sony Betamax recorder and the tapes subsequently analysed using the Alltek Brompton Encoder. This colour codes the grey scale image and allows better visual separation of tissue boundaries.
CASE 1

This patient presented at 2 days of age with cyanosis and tachypnoea. There was an ejection systolic mur믕 mur at the lower left sternal edge. The chest $x$-ray film showed cardiomegaly with diminished lung vascula 5 markings. The electrocardiogram showed right ven tricular hypertrophy with depressed ST segments and a delta wave indicative of intraventricular conduction disturbance. Arterial $\mathrm{O}_{2}$ in $100 \% \mathrm{O}_{2}$ was $6.4 \mathrm{kPa}$. The echocardiogram showed a large tumour filling the right ventricle. It obstructed both the inflow and the outflow of the right ventricle. The pulmonary valve could be seen. It was opening with ventricular systole but the subpulmonary region appeared completely obstructed by the tumour. The right ventricula? tumour was attached to the ventricular septum which. bulged into, and obstructed, the left ventriculap outflow tract. Using the colour encoder three further tumour nodules could be shown within the left veno tricular cavity (Fig. 1). These findings strongly sug gested a diagnosis of tuberous sclerosis. At operation $\bar{q}$. multilobulated large tumour was found within the right ventricle and was attached to the ventricular $\operatorname{sep}_{\tilde{r}}$ tum. The mass could only be partly removed an\$ right ventricular contraction could not be re $e_{\bar{\sigma}}^{\omega}$ established after operation.

Necropsy confirmed the presence of three furthe? macroscopical tumours within the left ventricle. His $\Phi$ tology was that of rhabdomyomata. Tubers were als 0 found extensively throughout the brain.

\section{CASE 2}

This patient presented for further investigation at $\frac{1}{8}$ months of age. A cardiac murmur had been notice 

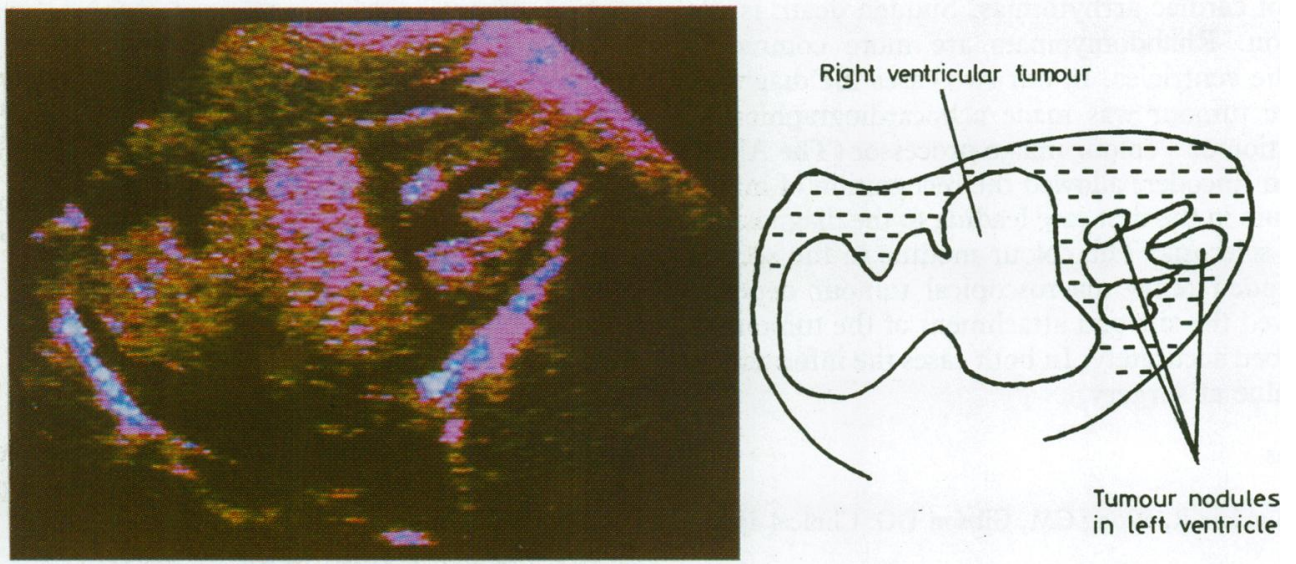

Fig. 1 The heart is viewed from the subxiphoid position with the transducer angled to display the tumour within the right ventricle and the three nodules of similar echogenic intensity within the cavity of the left ventricle.
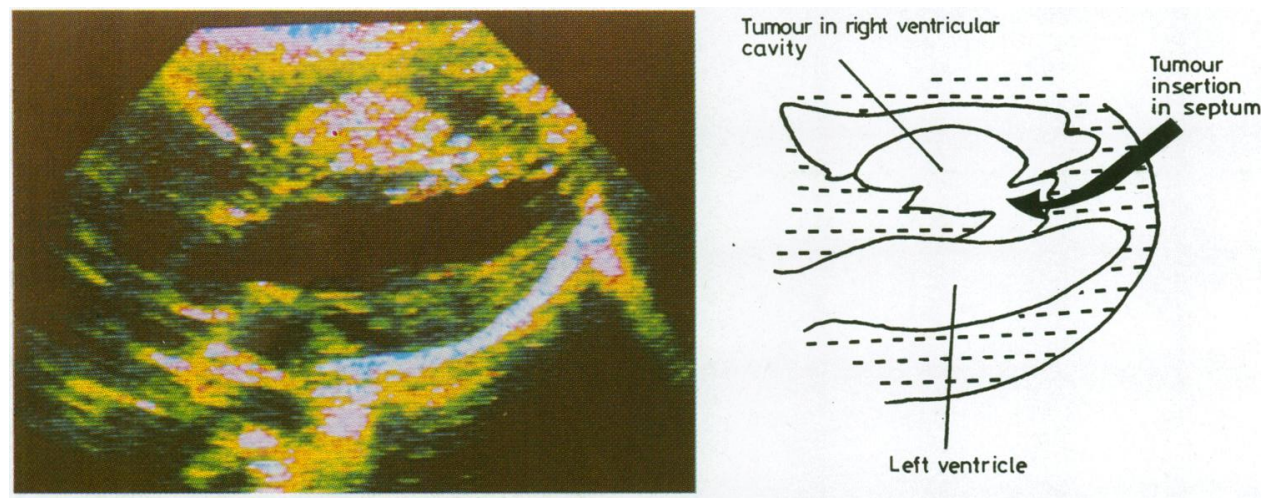

Fig. 2 The heart is viewed in the long axis of the left ventricle. The tumour can be seen within the right ventricular cavity and partially invading the lower part of the septum.

since birth. She was asymptomatic. Physical and mental development were normal. A grade $2 / 6$ pansystolic murmur could be heard at the left sternal edge. The electrocardiogram showed an axis of +90 and evidence of right ventricular hypertrophy. There was evidence of an intraventricular conduction defect. The chest $x$-ray film showed mild cardiomegaly.

The echocardiogram showed a large tumour within the body of the right ventricle. It was not mobile and was fixed to the ventricular septum. It lay just above the chordal attachments of the tricuspid valve. Using the colour module, the site and extent of the attachment of the tumour to the ventricular septum could be clearly delineated (Fig. 2). At operation the tumour was found to be merged with the septal myocardium and closely related to the tricuspid valve apparatus. The relation and attachment suggested on the echocardiogram were entirely confirmed surgically. The histology was that of a rhabdomyoma.

\section{Discussion}

The incidence of cardiac tumours presenting in infancy is low. McAllister and Fenoglio ${ }^{2}$ described 48 cases seen in the first year of life. Over half the cases were found to be rhabdomyomata. These tumours may be assumed to occur always in association with tuberous sclerosis whether this condition is clinically manifest or not. ${ }^{3}$ The lesions are also almost always multiple though in some instances multiplicity can only be detected microscopically. They may present because of obstruction to cardiac blood flow or 
because of cardiac arrhythmias. Sudden death is not uncommon. Rhabdomyomata are more commonly seen in the ventricles. In our two cases the diagnosis of cardiac tumour was made echocardiographically. The addition of a colour image processor (The Alltek Brompton Encoder) allowed the recognition of multiple tumours in the first case leading to the diagnosis of tuberous sclerosis. The colour module in the second case excluded other macroscopical tumour deposits and allowed the site and attachment of the tumour to be described accurately. In both cases the information was of value at surgery.

\section{References}

1 Logan-Sinclair R, Wong CM, Gibson DG. Clinical appli- cation of amplitude processing of echocardiographic. images. Br Heart $\mathcal{F}$ 1981; 45: 621-7.

2 McAllister MA Jr, Fenoglio JT Jr. Tumors of the cardiovas cular system. (Atlas of tumor pathology, second series.? Washington DC: Armed Forces Institute of Pathology은 1978.

3 Davies MJ. Tumors of the heart and pericardium. In $\mathbb{D}$ Pomerance A, Davies MJ, eds. The pathology of the heart ov London: Blackwell, 1975: 423-40.

Requests for reprints to Dr Lindsey $D$ Allan Department of Paediatric Cardiology, Guy's Hospitalị London SE1 9RT. 